\title{
Best tests for candidates
}

\author{
Science in presidential debates? Absolutely. A science debate? Not so sure.
}

M any of the great and good in US science - from the National Academies to Nobel laureates and various journals, including some parts of the Nature Publishing Group - have joined an initiative calling for the American election campaigns to feature a science debate. Such is the groundswell of support that their call is starting to feel like an idea whose time has come, and indeed it may prove to be so. You can join the throng at www.sciencedebate2008.com.

But in true scientific spirit, the proposal itself requires critical scrutiny - see, for example, page 621. And the campaign's website goes too far in saying that science and technology "may be the most important social issue of our time". In reality, science and technology are a factor in many issues, sometimes a defining one, but most often not. They can and must inform political debate, but will rarely be at its centre.

Take the key issue of climate change, which is at the top of the science debate list. The Bush administration's self-interested denialism and subsequent heel-dragging have infuriated informed opinion at home and abroad. But this anger, widely felt by scientists and others, should not lead us to raise science above other concerns out of a sense of slight. The science of the Earth system is crucial to understanding climate change; that does not mean that climate is best debated as a science issue.

Climate change should indeed be debated by the ultimate contenders for the presidency. The optimum format would allow them to question each other freely, with expert interlocutors able to challenge claims and highlight both common ground and inconsistencies. Scientific issues - how to deal with the uncertainties of climate sensitivity when deciding goals for emissions, or how far to shift federal research priorities towards near-to-medium-term innovation in alternative-energy systems - would play a key role in such a debate. But they would not be the whole story: tax policy, international trade, treaty law and foreign policy are just as crucial.

A similar approach, with candidates interacting with experts as well as each other, could be applied in other areas that are both of concern to scientists and significantly dependent on scientific data and research. The provision of health care, the encouragement of economic growth and the avoidance of nuclear proliferation are obvious possibilities.
Tests of the candidates' mettle might go further. In 2001, Democratic senator Sam Nunn played the role of the president in a much reported war-game, Dark Winter, which simulated a bioterrorist smallpox attack (the terrorists won). If the voters want a sense of how the presidential hopefuls respond to rapid influxes of technical expertise, why not ask the candidates and their chosen staff to submit separately to some similarly gnarly scenario containing a strong dose of science in front of the cameras. Aired back-to-back, the war games would undoubtedly make riveting viewing, and might reveal more

"Science and technology can and must inform political debate, but will rarely be at its centre." about a candidate's relation to scientific expertise - knowing how to ask questions, how to value responses, how to face uncertainties - than an opportunity to discuss the science budget (see page 610).

Turning a presidential campaign into a reality-TV version of 24 is obviously far fetched, and not necessarily desirable. But any sort of science debate is quite a stretch from business-as-usual. Well meant though it may be, the idea of Tim Russert or some other journalistinterrogator looking Republican hopeful John McCain in the eye and asking "What balance will you seek in federal science funding between major-programme project research and investigator-initiated basic-research grants?" is somewhat fantastical.

It is also slightly disturbing. For all that it claims to be a 'grass-roots' phenomenon, the proposed debate can be seen as an attempt by various élite institutions to grab the microphone and set the agenda from the top down.

Proponents might respond that this is the only practical way in which these issues can be raised. If so, any success of the debate proposal will mark a failure as well: a long-term failure to have the important contribution of science play an appropriate role in all levels of political discourse, which cannot be blamed solely on the Bush administration. To rectify that will require the long-term and possibly grubby work of cultivating broad political constituencies. But that offers more certain sustainability. The debate, if it happens, may be a grand thing on the night, but what will it change?

\section{Working double-blind}

\section{Should there be author anonymity in peer review?}

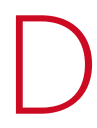
ouble-blind peer review, in which both authors and referees are anonymous, is apparently much revered, if not much practised. The Publishing Research Consortium (PRC) has assessed attitudes towards peer review among 3,000 academics in an international survey across the sciences and humanities. The results, released last month ${ }^{1}$, strongly affirm the value of peer review. They also highlight that $71 \%$ have confidence in double-blind peer review and that $56 \%$ prefer it to other forms of review. Support is highest with those who have experienced it (the humanities and social sciences) or where it is perceived to do the most good (among female authors). The least enthusiastic group is editors. So is it time for editors, and those at Nature in particular, to reconsider their position?

If referees know the authors' identities, it may leave the latter vulnerable to biases about them or their previous work, their gender, their nationality or their being new to an area of research. But the PRC survey supports the contention of Nature and others that identifying authors stimulates referees to ask appropriate questions 